\title{
Urban Archiving for Smarter Cities Archival practices beyond Open data
}

\author{
Elisabet M. Nilsson \\ School of Arts and Communication \\ Malmö University \\ Malmö, Sweden \\ elisabet.nilsson@mah.se
}

\author{
Veronica Wiman \\ Tromsø Academy of Contemporary Art \\ Tromsø, Norway \\ mail@veronicawiman.net
}

\begin{abstract}
Urban Archiving is a research theme within the project Living Archives exploring the roles of archives and archival practices in a digitized society. One of the aims is to create design interventions dedicated to exploring, prototyping and testing relevant possibilities for digital archives and archiving practices in various contexts, such as urban development. The research intervention presented in this paper explores and prototypes tools and archiving practices for capturing, representing, and disseminating the intangible culture heritage of a particular neighbourhood, or an area in a city. The data generated is of a qualitative kind, and can be used as a complement, or maybe even a provocation to the image of a neighbourhood outlined by open data sources. If urban open data can be useful in answering the "What?" of a city, the methods and tools we develop can help answering the "Why?" and thus deepen our understanding of urban areas, and how we can plan for sustainable cities.
\end{abstract}

Keywords-Smart City Learning; Intangible Cultural Heritage; Open Data; Urban Gardening Communities; Participatory Design; Artistic research; Archives; Archiving Practices

\section{LIVING ARCHIVES - URBAN ARCHIVING - URBAN GARDENING COMMUNITIES}

The research theme Urban Archiving is part of a multidisciplinary project called Living Archives ${ }^{1}$ exploring, analysing and prototyping archives and new archiving practices in a digitized society. The Urban Archiving theme specifically explores how archives and archiving practices can create cultural awareness and become a resource in urban sustainable development. To narrow down the window of exploration we initially chose to focus on the phenomenon of urban gardening, that is, the practices of growing plants, fruits and vegetables in an urban environment [1]. As a means to reach urban sustainability, urban gardening has in the last years of climate changes gained an increased attention, which also makes it an interesting area to look into in relation to our field of interest [2].

Our point of departure is the assumption that an urban gardening community can be "read" as an urban archive that captures, represents, and disseminates data and knowledge

\footnotetext{
${ }^{1}$ Project web site: livingarchives.mah.se, Accessed on 2015-06-14.
}

about a particular neighbourhood, or an area in a city. The urban garden is perceived as a performed memory expressed through the cultural background and experiences of the gardeners.

Thus, the kind of data that we are focusing on is of a qualitative kind, beyond the kind of quantitative urban open data often referred to in the context of smart cities learning and development.

\section{SMART CITY LEARNING BEYOND URBAN OPEN DATA}

What is open data? As put forward in the Open data handbook, open data is a resource that "that can be freely used, reused and redistributed by anyone-subject only, at most, to the requirement to attribute and sharealike" ${ }^{2}$.

Typical forms of urban open data sets may consist of data on: climate change, pollution levels, employment rate, energy use, various socio-economic factors, population, traffic, land use. Such open data generated from and captured about an area in a city is claimed to be a useful resource in urban planning, and in the process of developing what is often referred to as smart cities, and sustainable solutions on a structural level ${ }^{3}$.

The basic idea is that such urban open data sets can paint the big picture of an urban situation: where the most energy is consumed, what areas that are populated and depopulated, local temperature fluctuations, traffic congestions, levels of air pollution etc. These open data sources and archives can certainly be helpful in visualising the mountains and valleys of a city, and in answering questions starting with a what. However, if we want to zoom in, dive into a particular valley and smell a flower we need additional methods that can be applied when looking for answers to questions starting with a why. The assumption is that urban data of such kind may deepen our understanding of urban areas and the behaviour, and activities among the inhabitants, and thus be an important resource in urban development.

\section{THE AIM}

The aim of our work is to prototype and test tools and methods for answering questions about urban situations

\footnotetext{
${ }^{2}$ Open Data Handbook: opendatahandbook.org. Accessed on 2015-06-14.

${ }^{3}$ See e.g. UN Habitant Urban Data, http://urbandata.unhabitat.org/exploredata, and Open Knowledge Foundation, okfn.org, Accessed on 2015-06-14.
} 
starting with a why, and which can be used as a complement, or maybe even a provocation to the image of an urban area outlined by open data sources and archives. As already mentioned, we are focusing on the phenomenon of urban gardening, and thus the tools and methods developed are for capturing, representing, and disseminating urban archives in form of urban gardening communities.

\section{RESEARCH APPROACH AND PROCESS}

The project is of a multi-disciplinary kind assuming principles and methods from the fields of participatory design [3][5], and artistic research and practices [4][6]. The participatory design approach can in short be described as a diverse collection of principles and practices aimed at making technologies, tools, environments, businesses, and social institutions more responsive to human needs, inherently also including aspects of sustainable development. Our research approach is also informed by artistic and curatorial practices and research which suggest alternative models of citizen participation and tools for sustainable urban development. In line with Thompson we assume the view that "symbolic gestures can be powerful and effective methods for change" [6].

Our research process consists of a series of interventions conducted in form of design activities and artistic actions/gestures. The process results in a methodological toolkit containing a set of tools and methods for urban archiving practices. The toolkit is developed together with the urban gardening communities and artists we are collaborating with, and new tools and methods are added along the way.

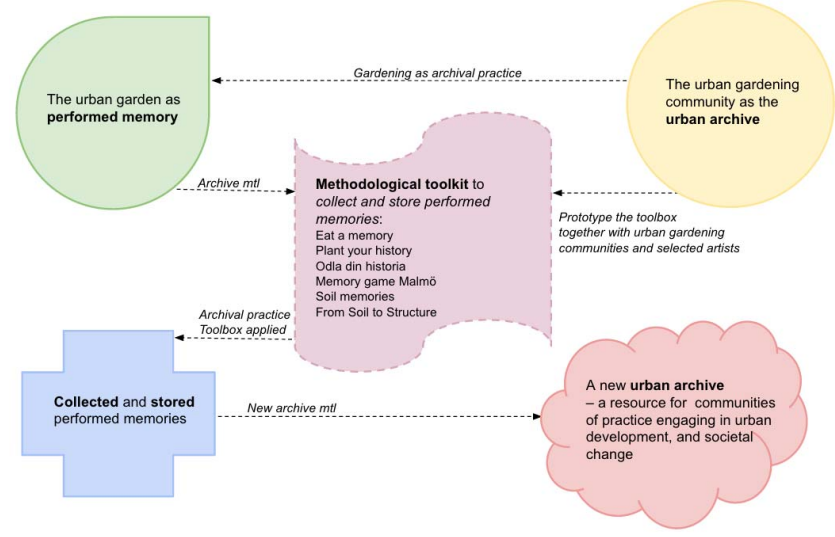

Figure 1. Overview of the project and research process.

\section{The Methodological toolkit: Methods And ToOlS}

The research interventions conduced so far have resulted in a collection of methods and tools that can be applied for gathering the intangible culture heritage of a particular neighbourhood, or an area in a city.

Eat a Memory is a method where eatables from urban gardens are part of exploring food and meals as performed memories, and cooking as archiving practice. Community members are invited to a meal in form of potluck where they bring a dish from their childhood memories on the topic "Your grandparents' gardens". The gathering is about performing memories by tasting flavours from their childhoods, and sharing these memories by sharing a meal.

In Plant your History urban gardening communities are invited to explore the notion of the garden as a performed memory. Questions asked are: "Can your personal history be planted in a garden? In what ways can a garden share stories beyond words about you, your family and your community?" Through an organic process we will develop an understanding of how to capture, and represent the urban garden as a performed memory.

Memory Game is developed in collaboration with an artist collective, and played together with community members. The idea is to use the game as a framework for both capturing, and disseminating background stories about the urban gardens and the gardeners.

Soil Memories is an act of collective storytelling. Soil contains particles and information about who we are and our path of life. Participants are asked to bring a scoop of soil, and tell us the story of this material and its meaning of place and time in your life.

As part our research and preparation we have organised the Greenhouse Artist Talks, which is a series of public talks where local and international artistic practitioners were invited to explore and present their work related to urban gardening. We have also organised From Soil to Structure, a two-day long program of cultural and artistic activities sharing and exchanging knowledge and practices about the topic of soil as a multi-layered open archive, an alternative source of open data and carrier of open knowledge.

\section{NEXT STEPS}

The methodological toolkit developed as part of our project can be described as a collection of methods tools for a more intimate kind of archiving practice, and way of collecting data about a community, or neighbourhood in a highly structured, but still personal way. We suggest that our methodological toolkit has the potential of becoming a tool for capturing intangible data about neighbourhoods, and communities, beyond traditional methods in the field of urban planning. The next step in our study is to invite urban planners to test, and re-design the toolkit in collaboration with residents and us.

\section{REFERENCES}

[1] Dziedzic, Nancy and Zott M., Lynn. Urban Agriculture. Greenhaven Press, Farmington Hills, MI, 2012.

[2] Gerst, Michael D., Raskin, Paul D. and Johan Rockstro m. Contours of a Resilient Global Future. Sustainability 2013, 6 (1). 123-135.

[3] Halse, Joachim, Brandt, Eva, Clark, Brendon and Binder, Thomas. Rehearsing the Future. The Danish Design School Press, Copenhagen, 2011

[4] Kester, Grant H. Conversation pieces: community + communication in modern art. University of California Press, Berkeley, CA. 2004.

[5] Simonsen, Jesper and Robertson, Toni. The Routledge Handbook of Participatory Design. Routledge, New York, NY, 2013

[6] Thompson, Nato (Ed.). Living as form: Socially Engaged Art From 1991-2011. Creative times books, MIT Press, New York, Cambridge, MA, 2012. 